\title{
V Festival Internacional de Teatro y Danza de Buenos Aires (2005)
}

\section{Paula Varsavsky}

A mediados de la década de los noventa, el gobierno de la Ciudad de Buenos Aires puso en marcha dos festivales: el Festival Internacional de cine independiente y el Festival Internacional de teatro y danza de Buenos Aires. Ambos resultaron de alta calidad. Desde del Teatro San Martín, uno de los complejos teatrales más grandes y completos de la Argentina, se organizó el primer festival internacional de teatro y danza que tuvo lugar en 1997. "Nos dijeron que no vendrían compañías ni de Europa ni de América del Norte porque estamos muy lejos," cuenta Graciela Casabé, directora del festival. Sin embargo, la realidad mostró lo contrario: vinieron 23 elencos extranjeros. Además, las secciones culturales de las diversas embajadas apoyan económicamente a grupos de teatro independiente o a figuras consagradas, como Laurie Anderson, en sus viajes y sus cachets. Tanto el Instituto Goethe como el British Council son auspiciantes indispensables del festival.

Hoy en día, se ha convertido en el referente que anheló ser. Decenas de programadores de festivales, actores, directores, dramaturgos, escenógrafos y periodistas especializados de todas partes del mundo llegan a Buenos Aires en septiembre de los años impares. La edición de 2005, del 7 al 25 de septiembre, no fue una de las mejores. Recibimos 12 compañías internacionales, mientras que en las últimas ediciones el número no bajaba de 20. En cuanto a otros países de América Latina, esta vez, solo asistió el Grupo de Rua de Niterói de teatro-danza brasileño con su espectáculo Telesquat.

En cuanto a las posibilidades de asistir al Festival, vale la pena un comentario. Las compañías extranjeras ofrecieron cuatro funciones de sus espectáculos a un precio de 25 pesos (nueve dólares). Las obras nacionales 
fueron gratuitas. Se entregaban dos entradas el día de la función a partir de las diez de la mañana. Sin embargo, había largas filas desde las seis de la madrugada. Las entradas se agotaban el día que salían a la venta. Para una ciudad con ocho millones de habitantes a la que se agregan visitantes extranjeros y de otras partes del país, resulta escaso. Termina sucediendo lo que no querría ser: un festín entre amigos. Los periodistas también ven su tarea dificultada. No importa el tipo de cobertura que realicen, dan tres entradas por periodista. Podría parecer justo, si no fuera porque periodistas políticos y amigos de los organizadores reciben todas las entradas que desean. Esto merecería algún tipo de estudio sociológico, sobre todo en una ciudad donde se ve muy buen teatro, por menos dinero de lo que cuesta una entrada de cine.

La selección de teatro local fue muy buena. Actualmente Buenos Aires tiene más teatros que Londres. La producción es vastísima. Los

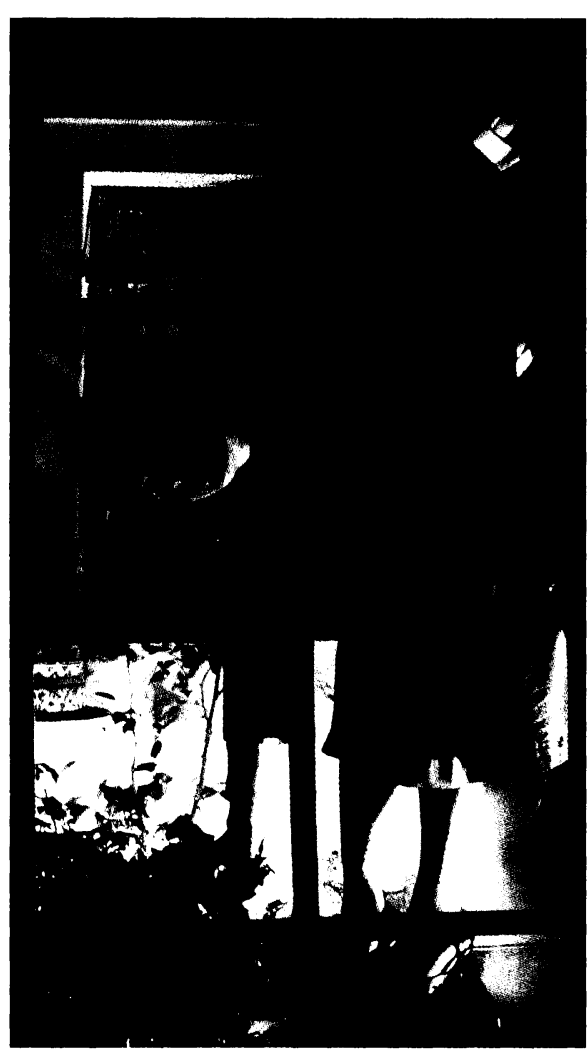

Divagaciones Foto de Melina Contantakos directores suelen ser también dramaturgos y actores. Esta práctica que comenzó a delinearse en el teatro postdictadura por talento de algunos o por falta de recursos de otros se ha establecido como norma. Tanto es así que en una conferencia en la edición del 2003, el director de la sección internacional de Royal National Theatre de Londres comentó, asombrado, que cuando armó su agenda de citas para su viaje a Buenos Aires, sabía que iba a ver a dramaturgos, directores y actores. Al llegar aquí tuvo la grata sorpresa de que citas se habían reducido a un tercio: cada persona cumplía los tres roles.

Una de las propuestas argentinas más interesantes resultó Divagaciones dirigida por Inés Saavedra. Basada en textos poéticos de Silvina Ocampo logra 


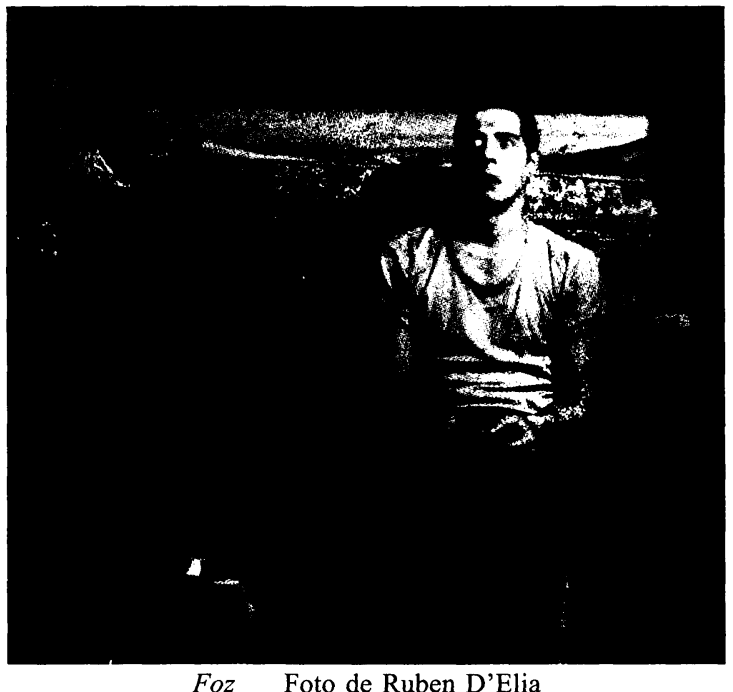

coherencia artística y un excelente ritmo narrativo. Las ajustadas actuaciones con perfecta dicción y un pianista en vivo, aciertan en encontrar la veta irónica de Ocampo sin perder la poesía.

En la escena porteña actual existe una fuerte tendencia de recreación de la nueva marginalidad. Se trata de una acentuada forma de pobreza que surgió a partir de la crisis económica del 2001. Foz de Alejandro Catalán es una muestra impecable de personajes de este grupo social. Un padre, un hijo y un "ayudante" van en una camioneta destartalada (que conforma íntegramente la escenografía) a Foz de Iguazú para hacer algún tipo de pequeño contrabando. En El sabor de la derrota dirigida y escrita por Sergio Boris, la decadencia económica se da en un ambiente rural. Se repite el trío de padre, hijo y ayudante. Ante la repentina aparición de una chica que se muestra interesada por mantener un romance con el peón, se produce un intenso desequilibrio entre los tres hombres.

En cuanto al director-dramaturgo, en un formato teatral quizá más clásico, una de las mejores obras fue Nunca estuviste tan adorable. Pieza algo autobiográfica de Javier Daulte, trata acerca de la historia del matrimonio de sus padres que comenzó en la década del cincuenta. Tanto el ascenso social como las relaciones humanas exudan oscuridad y manipulación. La clase media porteña de dos décadas consecutivas queda desnuda entre la carcajada y el horror. En la selección de obras argentinas hubo algunas omisiones, por ejemplo, el grupo Catalinas Sur, uno de los exponentes más impactantes del teatro barrial. Grupo de autogestión, con noventa y ocho actores en escena que ha sido invitado a España con su pieza El fulgor argentino.

Durante el festival, resulta estimulante la participación en mesas redondas sobre distintos temas: dramaturgia, dirección, música para teatro y programación de festivales, entre otras. El encuentro del teatro de América 
168

LATIN AMERICAN THEATRE REVIEW

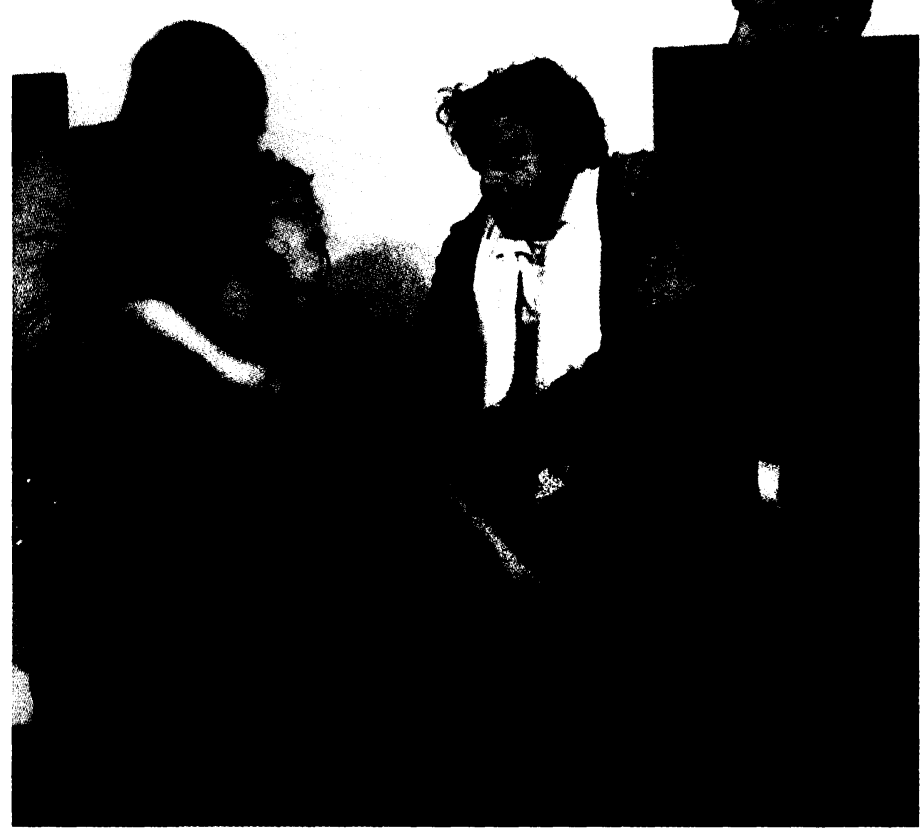

El sabor de la derrota Foto de Carlos Flynn

Latina con el Europeo resulta siempre intrigante. ¿Qué miran unos de otros? ¿Qué buscan? ¿Qué mitos circulan? Según Rafael Spregelburd (dramaturgo, director y actor argentino), estrenado varias veces en Europa, existe una idea tácita entre europeos y norteamericanos respecto de América Latina: "Ustedes hablan de sus crisis mientras nosotros creamos los mitos universales." A la pregunta sobre qué buscan en Canadá respecto de los espectáculos provenientes de América Latina, la respuesta de la programadora canadiense Tina Rasmussen es enfática: "Pasión," mientras que la programadora polaca Magda Grudzinska contesta: "Algo nuevo que nos quiere decir sobre la realidad." Las preguntas del público surgen en gran cantidad de acentos de países latinoamericanos y en portuñol.

Se han publicado varios libros muy valiosos con el apoyo del festival. En El teatro argentino en el IV Festival Internacional de Buenos Aires de Jorge Dubatti, el autor dice: "Podríamos afirmar que uno de los rasgos más frecuentes del Nuevo teatro argentino es la puesta en crisis de la noción de comunicación teatral: no hay comunicación (en el sentido de 
transmisión objetivista de un mensaje claramente pautado) sino creación de una ausencia, sugestión, contagio.... La construcción de sentido en la producción no se da como la ilustración de un saber previo sino como consecuencia de la poética: el sentido deviene, deriva a posteriori de la construcción poética" (Libros del Rojas, 2003). El Proyecto cruce resultó una de las áreas más elogiadas y parejas del festival. Se trata de una nueva sección donde directores, dramaturgos y artistas visuales hicieron intervenciones en lugares no convencionales. Una de ellas fue en el cementerio de la Recoleta.

En cuanto al panorama internacional, la selección, orientada al teatrodanza, tuvo sus mejores expresiones en el teatro. Valga la excepción del unipersonal de teatro-música y relato de Laurie Anderson que, además de tener el privilegio de inaugurar el festival, colmó las expectativas del público y prometió volver a Buenos Aires para repetirlo el año próximo. La versión belga de Tio Vania resultó maravillosa. Una puesta sumamente sencilla donde los actores ya se encuentran en escena cuando ingresa el público. Sentados cada uno en una silla, única escenografía durante el espectáculo de más de dos horas, el despliegue de actuación resultó impecable. Llevados al extremo, los personajes, carentes de solemnidad, lograban una expresividad suprema.

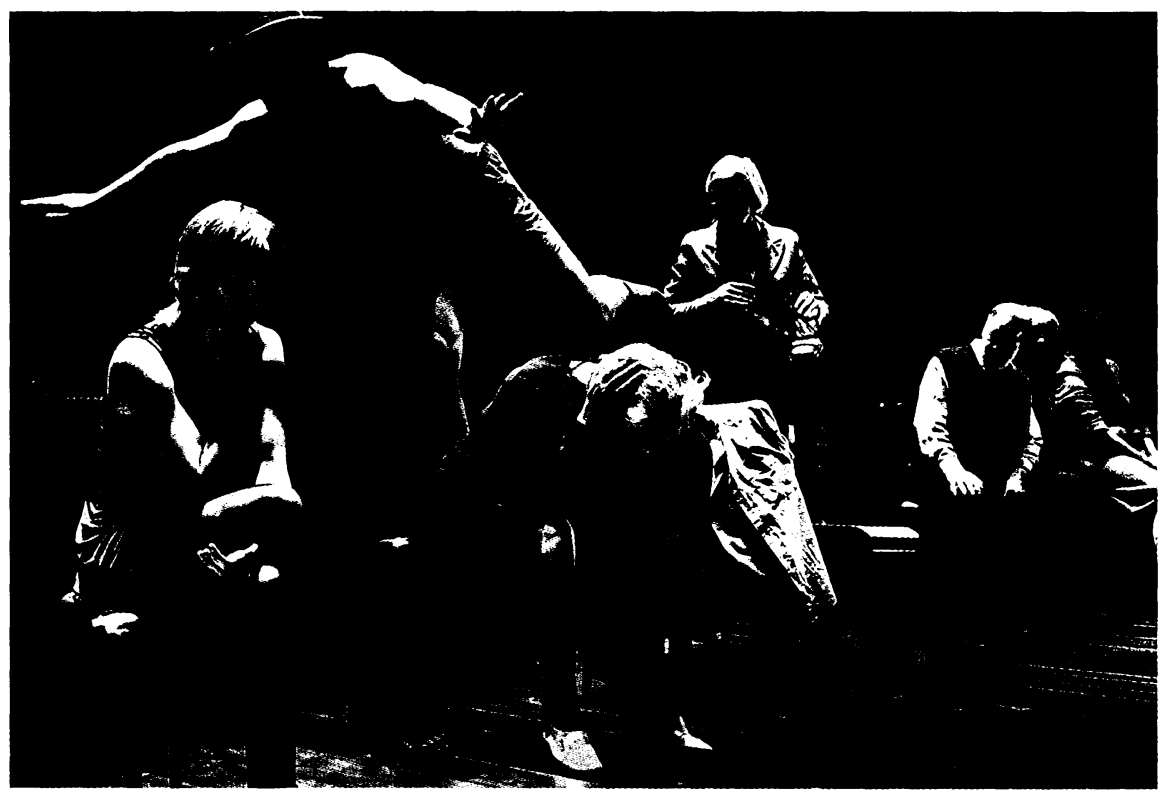


Entretenida, a pesar de que los subtítulos en el teatro molestan más que en el cine. El espectáculo de danza checo, Night Moth de la coreógrafa Petra Hauerová, tuvo partes interesantes, en particular la iluminación. Otra de las obras sumamente elogiadas por la crítica y el público fue Noche de reyes de la compañía inglesa Chekhov Internacional Theatre Festival y actuación del elenco ruso. La pieza alemana Endstation Amerika de Castorf prometía ser la vedette del festival, sin embargo, no causó el impacto esperado. La presencia del polémico director fue un evento en sí mismo. Las obras francesas no se lucieron, Display Píxel 3, una performance de música electrónica aburría hasta el cansancio. Algunos se fueron diciendo que había sido "una estafa."

Para completar el festival, no faltaron las Instalaciones. Una de ellas fue la iluminación de la fachada de la Alianza Francesa de Buenos Aires.

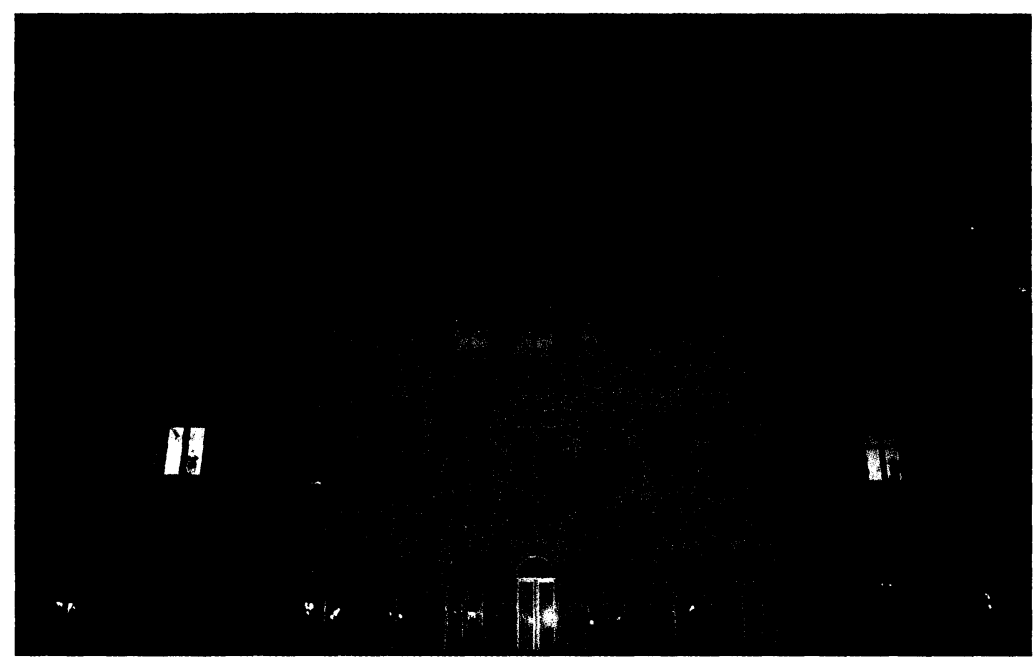

Foto de Carlos Furman

Durante una semana estuvo dominada por luces que asemejaban plantas. Se encendían al caer la noche y se movían al son del tránsito que pasa por la concurrida avenida donde se encuentra el edificio. Podríamos decir que daba un toque muy simpático al edificio de estilo francés. El festival es extenso, de incesante actividad. En la primavera de Buenos Aires resulta una cita imperdible. 